\title{
Effect of Vehicle-to-Grid on generation scheduling: in case of a collection of public holidays on the Japanese calendar
}

\author{
Nobuyuki Yamaguchi ${ }^{1,}$, Koki Kakimoto ${ }^{2}$, Nahoko Totsuka $^{2}$, Sekito Mizuno ${ }^{1}$, and Kogen Shibata ${ }^{1}$ \\ ${ }^{1}$ Tokyo University of Science, Graduate School of Engineering, 125-8585 Tokyo, Japan \\ ${ }^{2}$ Tokyo University of Science, Department of Engineering, 125-8585 Tokyo, Japan
}

\begin{abstract}
With the increase in the amount of photovoltaic power generation (PV) introduced, measures to respond to PV output fluctuations by Vehicle to Grid (V2G), which connects storage batteries of electric vehicles (EV) to the power system, have been studied. Since the usage status of many car changes on weekdays and holidays, the effects of V2G may be evaluated more accurately by considering weekly operation in addition to daily operation. In this study, we will quantitatively evaluate the effects of considering EVs that can be used for the weekly operation of a power supply group, including hydropower plants, in case of a collection of public holidays on the Japanese calendar.
\end{abstract}

\section{Introduction}

Nowadays, because global warming and the depletion of fossil are concerned to be getting serious, energy usage is shifting to electrification in every field, especially the automobile industry. The Japanese government has a plan to increase the capacity of Photovoltaics (PV) continuously [1]. On the other hand, large scale capacity of PV causes partial operation of the conventional fossil power plants in order to maintain the ability of adjustment of electric power supply-demand against intermittent power output from PV. This partial operation results in augmentation of fuel cost and carbon dioxide emission because the number of operating thermal power plants rises and generation efficient declines. Besides, PV output brings unprecedented deterioration of daytime load factor and generation of surplus electric power.

In Japan, a collection of public holidays called Golden Week in early May is an abnormal week from the viewpoint of electric supply and demand in the situation of large-scale PV penetration. Since Golden Week is a holiday, the demand for electricity is small, and it is close to the summer solstice, so there is a lot of solar power output. Therefore, if solar power can be stored into a battery in Golden Week, a reduction of fuel cost and carbon dioxide emissions would be expected.

In this study, the authors are studying how to achieve load leveling by connecting electric vehicles to the power system (Vehicle-to-Grid, V2G) and storing power like a pumped-storage hydropower plant. If the number of electric vehicles (EVs) increases in the future, the output and capacity of the entire electric vehicle will increase, which will have a significant impact on load leveling of the power system. Because the usage of EV might be changed on weekdays and weekends, this study investigates how the weekly operation of power plants, including pumped storage power plants and EVs, affects the fuel cost and carbon dioxide emission from the electric power industry and transportation sector in Japan in 2030.

\section{V2G system and its merit}

\subsection{V2G system and its merit}

According to the NREL report [2], each vehicle connects to the electric power grid, at which point the grid systems operator can control the charging and discharging of the vehicle's battery in the V2G concept. Many V2G projects are demonstrated, including in Japan [3], [4].

\subsubsection{Load leveling}

Electricity demand differs significantly not only in day and night but also on weekdays and holidays. Therefore, load leveling that absorbs load fluctuations and improves equipment utilization is valid on the time horizon of day and week. As mentioned above, Golden Week in Japan, which is a week contains a collection of the public holidays in early May, is one of the most severe weeks from the viewpoint of operation of pumped-storage power plants and the V2G batteries. Fig. 1 shows the electricity demand in Golden Week in 2016.

The first half of this week has many holidays, and electricity demand is small. On the other hand, the second half of the week is a weekday, and demand is high. Therefore, load leveling is achieved by storing power as much as possible in the first half of this week and using that power in the second half of this week. At this time, if not only the ordinary used pumped-storage power plants but also the EV batteries can be utilized, it is expected that

* Corresponding author: n-yama@rs.tus.ac.jp 


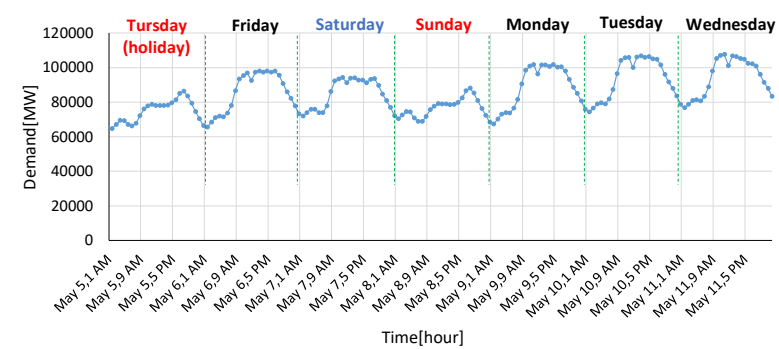

Fig. 1. Electricity demand in Golden Week in Japan in 2016

the power generation capacity that should be held socially would be reduced.

\subsubsection{Effective usage of surplus PV output}

In Japan, PV has been introduced in large quantities due to the FIT system that began in 2012. According to the statics of the Japanese government, up to March 2019, a total of 7.914 million $\mathrm{kW}$ was installed, and 44.56 million $\mathrm{kW}$ of PV has already been in operation. In the spring and fall, when electricity demand is low, if the weather is good, the output of PV power generation may increase, and surplus electricity may be generated [5]. When surplus power is generated, PV output is suppressed. If EVs are introduced in large quantities, the gasoline consumption in the transport sector will replace electricity consumption, boosting electricity demand and reducing the need for PV output suppression. Also, if $\mathrm{V} 2 \mathrm{G}$ becomes widespread, it will be possible to shift the time of generated power.

\subsection{Penetration and usage of EVs}

V2G uses EV storage batteries that are parked. Therefore, in order to examine the effects of $V 2 G$, it is necessary to consider how automobiles are used daily. The usage of automobiles is as follows. On weekdays, the usage is concentrated in the morning, noon, and evening. The usage in the morning and evening are for commuting. In the daytime, it is used by a business. On holidays, on the other hand, many automobiles are used in the daytime for shopping and entertainment [6].

Since the launch of mass-produced EVs in September 2009 in Japan, the EV market has been steadily expanding with improved performance, such as the extension of cruising distance. However, the current number of EVs in Japan is about 100,000 passenger cars. Freight cars have only just begun mass production, and are not yet in widespread use. The Long-term Energy Supply and Demand Outlook determined by the Comprehensive Resource and Energy Study Committee in Japan describes that the number of EVs and PHVs will be expected to be $16 \%$ of the total number of cars.

\section{Formulation of V2G storages and generation scheduling}

In this study, the authors execute unit commitment for day-ahead generation scheduling, including pumpedstorage hydropower plants in order to investigate that V2G effects on the fuel cost and carbon dioxide emission.
The assumed power systems consist of some control areas which are connected by interconnection tie lines.

\subsection{The objective function and constraints of Unit Commitment}

The objective function represents a minimization program of fuel costs of thermal power plants and penalty factors regarding suppression of PV output, power shortage, and the usage of tie lines as follows:

$$
\begin{aligned}
& \text { Min } F=\sum_{\text {areai }} \sum_{t} \sum_{g}\left[C_{g, \text { areai }}^{s u} v_{t, g, \text { areai }}\right. \\
& +\left(C_{g, \text { areai }}^{n l}+a_{g, \text { areai }}^{f c}\right. \\
& \left.+C_{g, \text { areai }}^{\text {CO2f }}\right) u_{t, g, \text { areai }} \\
& +\left(C_{g, \text { area }}^{g}+C_{g, \text { areai }}^{\text {Co2fb }}\right) p_{t, g \text {,areai }}^{g} \\
& +C^{s p t} p_{t, S P T, \text { areai }}+C^{s p r} p_{t, S P R, \text { areai }} \\
& +C^{S h} p_{t, S H, \text { areai }}+C^{\text {resUP }} p_{t, S H, \text { areai }}^{\text {resUP }} \\
& +C^{\text {resDOWN }} p_{t, S H, \text { areai }}^{\text {resDown }}+C^{\text {tie }} p_{t, \text { tie }}^{\text {planPlus }} \\
& \left.+C^{\text {tie }} p_{t, \text { tie }}^{\text {planinus }}\right]
\end{aligned}
$$

Where, $g$ and $i$ represent the indies of the thermal power plant and control area, respectively. A time interval is an hour in this study. The constants in Eqn. (1) are as follows: $C_{g, \text { areai }}^{\text {su }}$ : startup cost [JPY],

$C_{g, \text { areai }}^{n l}+a_{g, \text { areai }}^{f c}:$ no-load operation cost [JPY],

$C_{g, \text { are }_{i}}^{g}$ : coefficient of fuel cost [JPY/MW],

$C_{g, a r e a i}^{C O 2 f b}, C_{g, \text { areai }}^{C O 2 f c}$ : penalty of carbon dioxide [JPY/MW],

$C^{\text {spt }}$ : a penalty of a surplus generation not from renewable energy resources [JPY/MW],

$C^{S p r}$ : a penalty of a surplus generation from renewable energy resources [JPY/MW],

$C^{\text {sh }}$ : a penalty of power shortage [JPY/MW],

$C^{\text {resUP }}$ : a penalty of a shortage of upward regulation control capacity [JPY/MW],

$C^{\text {resDOWN }}$ : a penalty of a shortage of upward regulation control capacity [JPY/MW],

$C^{\text {tie }}$ : a cost of usage of the interconnection tie lines [JPY/MW].

The variables should be solved as follows:

$p_{t, g, \text { areai }}^{g}$ : generating output from power plant $g[\mathrm{MW}]$,

$p_{t, S H, \text { areai }}$ : a surplus generation not from renewable energy resources [MW],

$p_{t, S P R, \text { areai }}$ : a surplus generation not from renewable energy resources [MW],

$p_{t, \text { SPTareai }}$ : power shortage $[\mathrm{MW}]$,

$u_{t, \text { g,areai }}, v_{t, \text { g,areai }}, l_{t, \text { g,areai }}:$ binary variables express operation status, startup status, and shutdown status, respectively,

$p_{t, S H, \text { areai }}^{\text {resUP }}, p_{t, S H, \text { areai }}^{\text {resDow }}:$ relax variables regarding upward/downward regulation control capacity [MW],

$p_{t, t i e}^{\text {plan }}{ }^{\text {plus }}$ : relax variables regarding forward tie-line flow [MW],

$p_{t, \text { tie }}^{\text {planMus }}$ : relax variables regarding reverse tie-line flow [MW].

The constraints in this program represent the power balance of supply and demand, maximum and minimum generating output, the capacity requirement of upward 
and downward regulation control, the minimum uptime and downtime of the thermal power plants, the capacity of tie lines, and the capacity of pumped hydropower plants.

\subsection{Mathematical modeling of EVs}

Before the formulation of EVs, some assumptions regarding the type of vehicles and batteries are described. This study considers only passenger and freight cars, which share $93 \%$ of the number of cars in whole registered cars in the government. This means that special cars and motorcycles are not considered. The usages of the cars are only going to work, returning home, and business. The sizes of cars are ordinary cars, small cars, and light cars of which the displacement must be less than $660 \mathrm{ccs}$ in the legislation of Japan.

In our unit commitment program, The EV's batteries are assumed as one large battery in which capacity changes depending on the ability of the EVs in the same control area. As mentioned above, EV's batteries are available only when the EV parked. The followings are the constraints regarding EV batteries.

-Equal constraint on stored energy in the battery:

$e_{t, b, \text { areai }}^{\text {rem }}=e_{t-1, b, \text { areai }}^{\text {rem }}+\gamma_{b} \cdot p_{t-1, b, \text { area }_{i}}^{C}-\frac{p_{t-1, b, \text { area }_{i}}^{D}}{\eta_{b}}-$
$E_{t-1, b, \text { area }}^{\text {drive }}$

-The initial condition of stored energy in the battery:

$$
e_{\text {start }, \text {, }, \text { areai }}^{\text {rem }}=E_{\text {base }, \text { b, areai }}^{\text {rem }}
$$

-The terminal condition of stored energy in the battery:

$$
e_{\text {end, }, \text {, areai }}^{\text {rem }}=E_{\text {base }, \text {, }, \text { areai }}^{\text {rem }}
$$

-The minimum stored energy in the battery:

$$
\frac{p_{t, b, a r e a i}^{\text {resUP }}}{\eta_{b}}+E_{t, b, \text { areai }}^{\text {capamin }} \leq e_{t, b, \text { areai }}^{\text {rem }}
$$

-The maximum stored energy in the battery:

$$
e_{t, b, \text { areai }}^{\text {rem }}+\frac{p_{t, b, a r e a i}^{\text {resDoWN }}}{\eta_{b}} \leq E_{t, b, \text { areai }}^{\text {capamax }}
$$

-The maximum output for downward and upward regulation control of power grid from EVs:

$$
\begin{aligned}
& p_{t, b, \text { areai }}^{\text {resoWN }} \leq P_{p, \text { area }}^{\text {Cmax }}-p_{t, p, \text { are }_{i}}^{C}+p_{t, p, \text { area }_{i}}^{D} \\
& p_{t, b, \text { areai }}^{\text {resUP }} \leq P_{b, \text { area }_{i}}^{\text {Dmax }}+p_{t, b, \text { area }_{i}}^{C}-p_{t, b, \text { area }_{i}}^{D}
\end{aligned}
$$

-The maximum power output from EVs with an exclusive binary variable:

$$
\begin{aligned}
& p_{t, b, \text { areai }}^{D} \leq r c c_{t} \cdot P_{b, \text { areai }}^{\text {Dmax }} \cdot \delta_{t, b, \text { areai }} \\
& p_{t, b, \text { areai }}^{C}+p_{t, b, \text { area }_{i}}^{\text {Cdrive }} \leq P_{b, \text { area }_{i}}^{\text {Cmax }} \cdot\left(1-\delta_{t, b, \text { area }_{i}}\right)
\end{aligned}
$$

Where $b$ means the index of battery, and:

$\gamma_{b}$ : efficiency of charge to the battery,

$\eta_{b}$ : efficiency of discharge from the battery,

$E_{t, b, a r e a i}^{\text {capamin }}:$ the minimum capacity of the battery [MWh],

$E_{t, b, \text { areai }}^{\text {capamax }}$ : the maximum capacity of the battery [MWh],

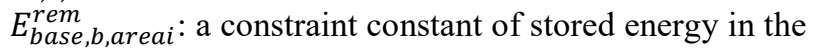
battery [MWh].

The variables are as follows:

$p_{t, b, a r e a i}^{\text {resDOWN }}, p_{t, b, a r e a i}^{\text {resUP }}:$ dwnward and upward regulation control of power grid from EVs [MW],

$p_{t, p, \text { area }_{i}}^{C}, p_{t, p, \text { area }_{i}}^{D}$ discharge / charge power [MW],

$e_{t, b, a r e a i}^{r e m}$ : stored energy in the battery [MWh],

$\delta_{t, b, \text { area }_{i}}$ : a binary variable representing the mode of the battery (0: discharge, 1: charge).

\section{Numerical experiments}

\subsection{Assumptions}

\subsubsection{Electric Power systems}

The test system consists of 9 control areas and ten interconnection points which model the Japanese power system. In this system, there are 356 thermal power plants, 19 hydropower plants, 19 pumped hydropower plants, and EV batteries for each control area. The output from nuclear power plants and renewable energy resources are subtracted from electricity demand in advance. The unit commitment is solved each day for 365 days.

\subsubsection{EV parameters}

(1) The number of EVs and the battery performance:

The EV penetration rate for passenger cars was set at $16 \%$, the target for 2030 , and the penetration rate for freight cars was set at $8 \%$, half of the penetration rate for passenger cars. Tables 1 and 2 show the proportions and battery performance of three types of passenger cars and three types of freight cars.

(2) The rate of usage:

It is necessary to consider what percentage of passenger cars and freight cars are used. For passenger cars, the ratio of use by area was calculated using the ratio of means of transportation used for commuting by prefecture. For freight cars, we could not find the usage ratio by prefecture, so we decided to use $70 \%$ for all nine areas nationwide. Regarding the percentage of passenger cars used on holidays, the outing rate is $80.9 \%$ on weekdays and $59.9 \%$ on holidays, while the traffic rate ratio is $45 \%$ on weekdays and $61.6 \%$ on holidays. We assumed that the number of cars with almost the same number was the same, and used the same usage ratio as on weekdays. On the other hand, the holiday use rate of freight vehicles is said to be $30 \%$ lower than the use rate on weekdays.

(3)The aim and profile of usage:

Passenger cars were considered to be commuting, work, returning home, and sightseeing and shopping on weekdays. The freight car was considered to be used for work on both weekdays and holidays. Based on Japanese government statistics, we created and used weekday (Fig.

Table 1. Parameters of passenger car

\begin{tabular}{|l|c|c|c|}
\hline Type of car & $\begin{array}{c}\text { Share } \\
{[\%]}\end{array}$ & $\begin{array}{c}\text { Capacity } \\
{[\mathrm{kWh}]}\end{array}$ & $\begin{array}{c}\text { Range per enegy } \\
{[\mathrm{km} / \mathrm{kWh}]}\end{array}$ \\
\hline $\begin{array}{l}\text { Ordinary } \\
\text { car }\end{array}$ & 31 & 40 & 8 \\
\hline Small car & 33 & 40 & 8 \\
\hline Light car & 36 & 16 & 10 \\
\hline
\end{tabular}

Table 2. Parameters of freight car

\begin{tabular}{|l|c|c|c|}
\hline Type of car & $\begin{array}{c}\text { Share } \\
{[\%]}\end{array}$ & $\begin{array}{c}\text { Capacity } \\
{[\mathrm{kWh}]}\end{array}$ & $\begin{array}{c}\text { Range per enegy } \\
{[\mathrm{km} / \mathrm{kWh}]}\end{array}$ \\
\hline $\begin{array}{l}\text { Ordinary } \\
\text { car }\end{array}$ & 31 & 40 & 8 \\
\hline Small car & 33 & 40 & 8 \\
\hline
\end{tabular}




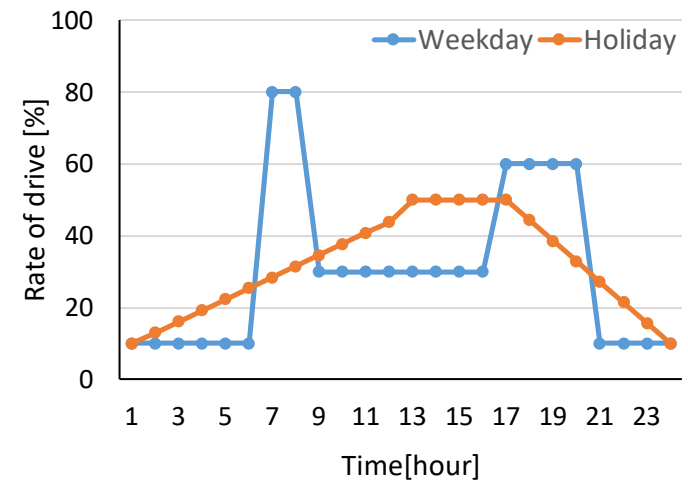

Fig. 2. Profile of passenger car

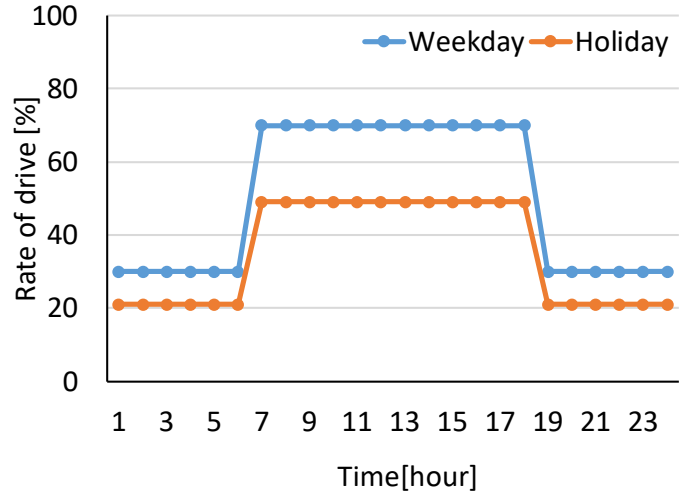

Fig. 3. Profile of freight car

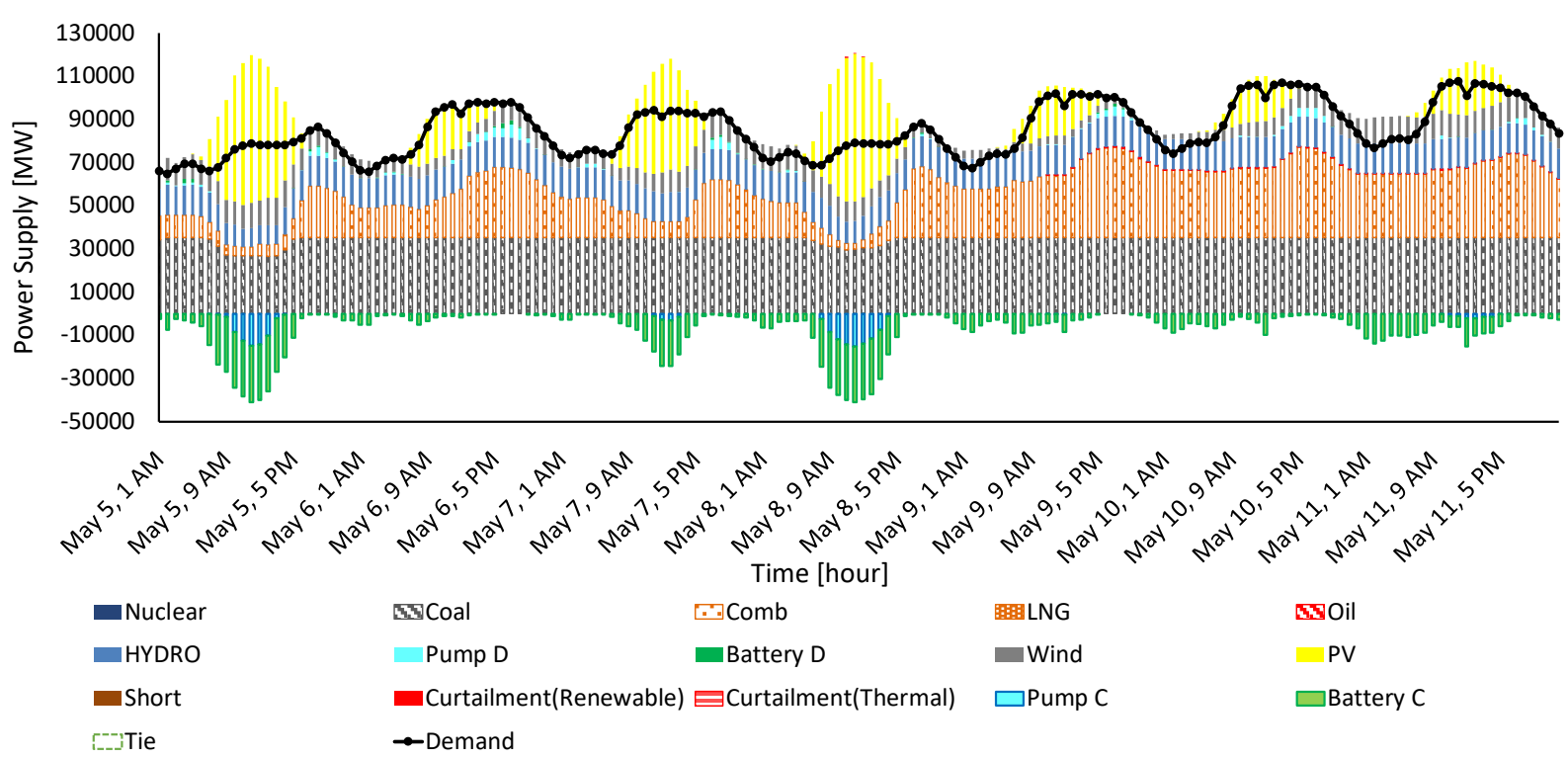

Fig. 4. With V2G, generation schedule on the representative week (case 1)

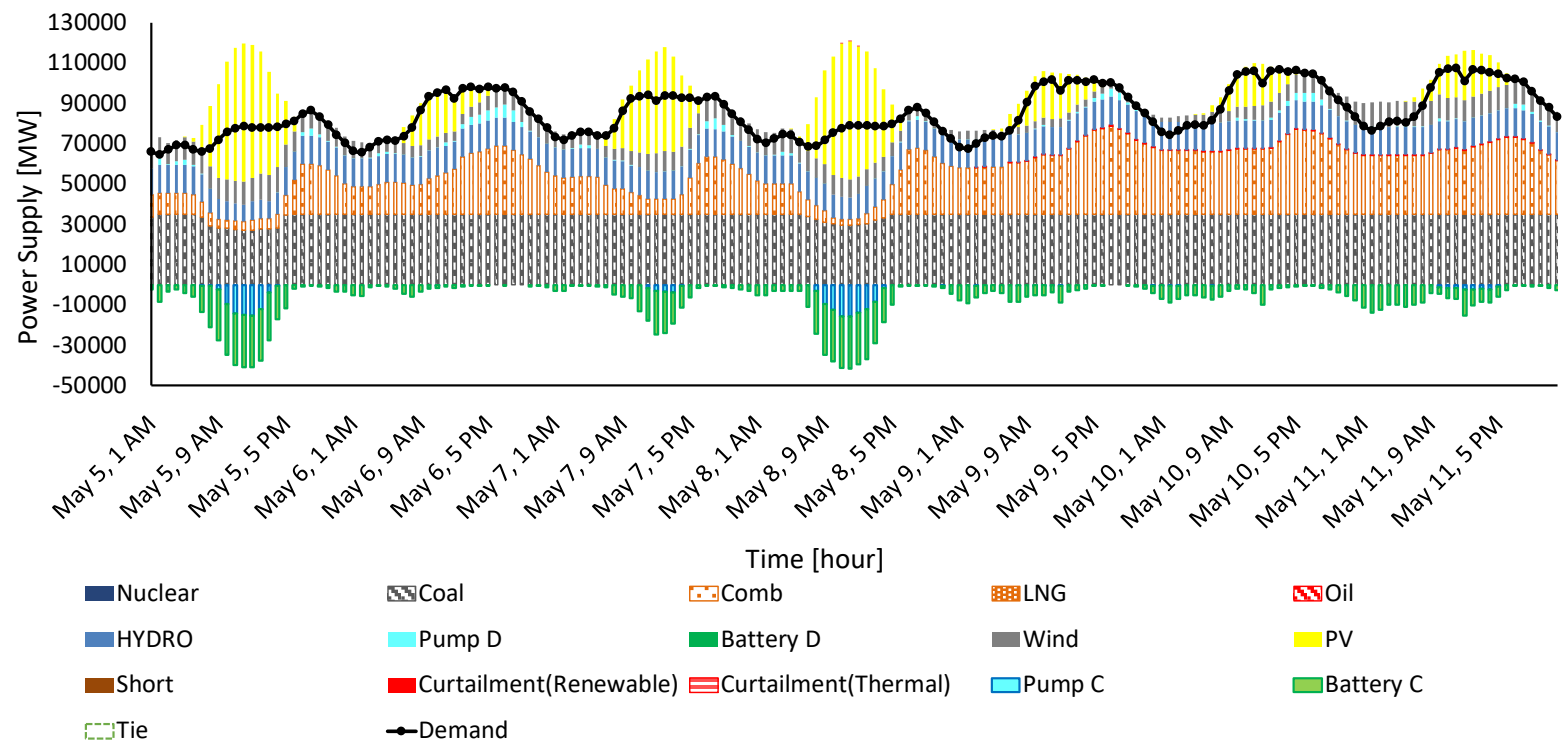

Fig. 5. Without V2G, generation schedule on the representative week (Case 2)

2) and holiday (Fig. 3) usage profiles for passenger cars and freight cars.

(4) The electric energy for drive:

The average nationwide commuting time is 37.8 minutes, and it can be considered that few people commute to work for more than one hour. Therefore, the mileage was calculated by the average speed $(\mathrm{km} / \mathrm{h}) \mathrm{x}$ average commute time (h) for each prefecture, and the power consumption was calculated by dividing this distance by the electricity cost. For holiday cars, the travel 
Table 3. The number of power plants which are in maxoutput operation and partial operation

\begin{tabular}{|c|c|c|c|c|}
\hline & \multicolumn{2}{|c|}{ Case1 } & \multicolumn{2}{c|}{ Case 2 } \\
\hline & Max. & Partial & Max. & Partial \\
\hline Area A & 1007 & 6 & 1008 & 11 \\
\hline Area B & 1899 & 9 & 1892 & 15 \\
\hline Area C & 5453 & 7 & 5465 & 0 \\
\hline Area D & 2254 & 22 & 2238 & 26 \\
\hline Area E & 599 & 0 & 598 & 1 \\
\hline Area F & 31123 & 0 & 3115 & 0 \\
\hline Area G & 2120 & 0 & 2121 & 0 \\
\hline Area H & 1616 & 5 & 1606 & 9 \\
\hline Area I & 3167 & 23 & 3211 & 35 \\
\hline
\end{tabular}

Table 4. Fuel cost, carbon dioxide emission, and load factor

\begin{tabular}{|c|c|c|}
\hline & Case1 & Case 2 \\
\hline $\begin{array}{c}\text { Fuel cost } \\
\text { [G Yen/week] }\end{array}$ & 59.10 & 59.15 \\
\hline $\begin{array}{c}\text { Carbon dioxide } \\
\text { emission [Mt/week] }\end{array}$ & 6.853 & 6.856 \\
\hline $\begin{array}{c}\text { Load factor } \\
\text { in the week [\%] }\end{array}$ & 74.50 & 72.89 \\
\hline $\begin{array}{c}\text { Fuel cost per demand } \\
\text { [Yen/kWh] }\end{array}$ & 3.837 & 3.840 \\
\hline
\end{tabular}

time for shopping was considered not to exceed one hour, so the same calculation method as above was used. In addition, we consider that passenger cars are always running during weekdays, freight cars on weekdays, and holidays because they are only considered for business use, and the average hourly speed $(\mathrm{km} / \mathrm{h})$ for each prefecture is divided by electricity costs. The amount of power consumption was obtained. For the average speed, the average speed in the urban area of the general road meter when the passenger car is crowded and the total average speed of the general road meter when the car is not crowded are used for the freight car.

(5) The rated output and the total size of storage of EV fleet:

The rated output is considered to be that the car that is not running is connected to the grid, and the number of units connected in each area is multiplied by $3 \mathrm{~kW}$ (calculated from the maximum voltage of household $200 \mathrm{~V}$ and the maximum current 15 A). did. However, EVs cannot be charged at offices and other places, and can only be charged at home. The maximum capacity is the sum of the battery capacity for each vehicle model multiplied by the number of vehicles.

\subsection{Results}

Figs. 4 and 5 illustrate the weekly generation schedule with and without $\mathrm{V} 2 \mathrm{G}$ on the representative week. The results means that V2G does not vary the weekly schedule dramatically.

Table 3 depicts the number of operating power plants. The figures are separated into the plants in maxmun output and in partial output. The efficiency of generation are better in maximum output than partial output. In case 1 , the number of power plants in partial operation obviously declines from case 2 . The effect of decrese in the number of operation is deffernt amang areas. The reason seems that the generation portfolio varies amang areas. The numer of the power plants in maximum output does not change significantly.

Table 4 shows the simulation results of fuel cost, carbon dioxide emission, and load factor. All of them changes better by V2G.

\section{Conclusion}

This study evaluates the effect of $\mathrm{V} 2 \mathrm{G}$ on generation schedule. V2G brings better results from the viewpoints of fuel cost, carbone dioxide emission and load factor. The various scenario regarding penetration, fossil fuel cost and so on should be examined in the future.

\section{References}

1. The ministry of the Environment, Viability report of distributed and renewable energy resources in 2050, the Government of Japan (2014)

2. D. Steward, Critical Elements of Vehicle-to-Grid Economics, National Renewable Energy Laboratory, NREL/TP-540069017 (2017)

3. Tokyo Electric Power Company Holdings, Inc., Implementation of Demonstration to Prove the Feasibility of V2G Aggregators, press release (2019)

4. Tohoku Electric Power Co., Inc., Virtual Power Plant Verification Project with the use of new information technology, press release (2018)

5. Kyushu Electric Power Co., Inc., Current State of the Renewable Energy in Kyushu Electric Powe and Our Future Plan (2017)

6. H. Nakamura, Holiday traffic characteristics and highway design schemes, IATSS Review, Vol. 19, No. 2, pp. 94-101 (1993) (in Japanese) 